\title{
Influência da via de parto na morbidade e mortalidade de conceptos em apresentação cefálica com
} peso entre 1000 e 2500 gramas

\section{Influence of delivery on morbidity and mortality in the newborns in the vertex presentation weighing 1000 and 2500 grams}

\author{
Autor: Ronney Antonio Guimarães \\ Orientador: Prof. Dr. Eduardo de Souza \\ Co-orientador: Prof. Dr. Luiz Camano
}

Tese apresentada à Universidade Federal de São Paulo - Escola Paulista de Medicina, para obtenção do título de Mestre em Obstetrícia, em 29 de março de 2003.

Objetivo: avaliar a influência da via de parto sobre a morbidade e mortalidade de recém-nascidos, em apresentação cefálica, com peso entre 1.000 e 2.500 gramas. Métodos: estudo retrospectivo, transversal, comparativo, que incluiu 743 prontuários, através dos seguintes critérios: trabalho de parto espontâneo; concepto em apresentação cefálica, com peso entre 1.000-2.500 gramas. Morbidade avaliada através do: índice de Apgar (menor que sete no $1^{\circ}$ e / ou $5^{\circ}$ minuto); diagnóstico de sindrome de desconforto respiratório e tempo de internação hospitalar (acima de quatro dias). Mortalidade neonatal: óbitos ocorridos após o parto até a alta hospitalar. Realizada análise estatística entre as vias de parto, em três grupos de peso (1.000-1500g; 1.500$2000 \mathrm{~g}$ e 2.000-2500g), comparando os fatores associados à morbidade com a via de parto, em cada grupo de peso. Utilizado testes de qui-quadrado e exato de Fisher. Resultados: a morbidade neonatal ocorreu em 22,6\% dos casos e foi significativamente maior $(\mathrm{p}=0,000)$ na cesariana em relação ao parto vaginal(29,6\% x 12,8\% respectivamente) no grupo de 2000-2500g. Quando analisada através do índice de Apgar no $1^{\circ}$. e $5^{\circ}$. minutos, não mostrou diferença significativa. Em relação à síndrome de desconforto respiratório e tempo de internação, ocorreu com diferença significativamente maior ( $p=0,010$ e $p=0,000$ respectivamente), neste mesmo grupo. A mortalidade intra-hospitalar teve baixa freqüência $(4,7 \%)$ e não mostrou diferença significativa em relação à via de parto. Conclusão: a orientação assistencial apurada é que a cesariana, per se, não contribuiu para o melhor desfecho neonatal nos conceptos de baixo peso, em apresentação cefálica.

PALAVRAS-CHAVE: Prematuridade; Restrição do crescimento intra-uterino; Parto normal; Cesariana; Mortalidade neonatal precoce

Resumo de Tese

\section{Mutação no exon 20 do gene da elastina em mulheres com incontinência urinária de esforço decorrente de fatores extrinsecos à uretra}

\section{Mutation in exon 20 elastin gene of women with extraurethral stress urinary incontinence.}

Autor: Hamilton Hourneaux Pompeu

Orientador: Prof. Dr. Aldo Junqueira Rodrigues Jr.

Co-Orientador: Prof. Dr. Ricardo Muniz Ribeiro

Tese de Doutorado apresentada ao Departamento de Clínica Cirúrgica da Faculdade de Medicina da Universidade de São Paulo, em 16 de março de 2004.

Desordens difusas do tecido conectivo podem estar implicadas na gênese da incontinência urinária de esforço (IUE) e alterações morfológicas das fibras elásticas têm sido descritas em associação à cistocele, prolapso uterino e hérnia inguinal. Recentemente foi demonstrada significativa correlação entre mutações pontuais no exon 20 do gene da ELN e hérnia inguinal em homens adultos. Como mutações do gene da ELN podem estar relacionadas à produção de moléculas alteradas da proteina, acarretando perda da propriedade de distensão reversivel do tecido conectivo do assoalho pélvico, o objetivo desse trabalho foi investigar a presença de mutações no exon 20 do gene da ELN em mulheres adultas com IUE decorrente de fatores extrinsecos à uretra, caracterizada por critérios clínicos e urodinâmicos previamente descritos. Estudouse o ácido desoxirribonucléico (DNA) genômico obtido do sangue de 40 mulheres com IUE e 37 mulheres continentes, pareadas por idade e paridade. O exon 20 do gene da ELN foi amplificado pela reação em cadeia da polimerase e seu polimorfismo avaliado preliminarmente por eletroforese em gel de poliacrilamida. O DNA foi seqüenciado e o resultado confrontado com o banco de dados do National Human Genome Research Institute. Foi observada troca da primeira base nitrogenada no códon 422 (AGT'TMGGT) em 27,5\% das mulheres incontinentes e em $35,1 \%$ das do grupo controle. Não houve significância estatística que indique ser a mutação en- 